\title{
Effect of Surface Modification by Ammonia Plasma on Vascular Graft: PET Film and PET Scaffold
}

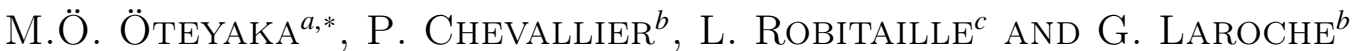 \\ ${ }^{a}$ Dumlupınar Üniversitesi, Mühendislik Fakültesi, Makine Bölümü, Merkez Kampüs, Kütahya, Turkey \\ ${ }^{b}$ Surface Engineering Laboratory, Department of Mining, Metallurgical, and Materials Engineering \\ Université Laval, Quebec, G1K 7P4, Canada \\ ${ }^{c}$ Industrial Materials Institute, National Research Council Canada, Boucherville, QC, Canada
}

\begin{abstract}
Nowadays, poly (ethylene terephthalate) (PET) textiles, either knitted or woven, are largely used as substitutes for replacement of medium and large calibre $(10-40 \mathrm{~mm})$ arteries. Unfortunately, these substitutes do not perform well when they are used to replace small diameter arteries due to thrombogenicity and compliance mismatch issues. Surface treatments were often used as the first step to solve thrombogenicity issues. For example, low pressure ammonia plasma processes can provide modification of the top $\approx 10-50 \AA$ of polymer surface without affecting bulk properties of materials. This work compared ammonia plasma surface modifications of PET film (flat surface) and PET scaffolds (porous surface). Plasma treatments lead to a higher amount of nitrogen as well as amino groups on scaffolds compared to films. N/C maximum was reached for PET film and scaffold after plasma treatments of $5 \mathrm{~s}$ and $100 \mathrm{~s}$, respectively. Highest amine concentration on films and scaffolds were obtained at short treatment time, specifically $1 \mathrm{~s}$. In addition, high resolution spectra of $\mathrm{C} 1 \mathrm{~s}$ confirmed that amino groups were mainly grafted on aromatic rings. Nodule formation was observed after plasma treatment with atomic force microscopy. Their size and shape increased with longer treatment time.
\end{abstract}

PACS: 52.40.-w, 52.77.Bn, 52.77.Fv, 52.80.Pi

\section{Introduction}

Today, artherosclerosis is the number one cause of morbidity and mortality in the developed country. This disease causes hardening of the arteries, diminishes flow in arteries, and it can also completely obstruct the blood flow. [1, 2]. Treatment is basically surgical and consists of bypassing the nonfunctional vessel segment to restore flow. Nowadays, poly (ethylene terephthalate) (PET) knitted or woven with coated (heparin or collagen) or no-coated is largely used as substitute for replacement of medium and large calibre $(10-40 \mathrm{~mm})$ arteries such as aortofemoral $[3,4]$. The complication with PET vascular graft in the area of small vascular graft are thrombogenicity [5], compliance mismatch [6] and true aneurysm [7]. The communications of endothelial cells (EC) with the polymeric surface begin with covalent immobilization of bioactive compound onto functionalized polymer surfaces. For that reason, surface treatments are the first step to enhance the biocompatibility of biomaterials $[8,9]$. In surface functionalisation, low pressure plasma processes can provide modification of the top $\approx 10-50 \AA$ of polymer surface without affecting bulk properties of materials. Surface modification by

\footnotetext{
* corresponding author; e-mail: moteyaka@dpu.edu.tr
}

ammonia $\left(\mathrm{NH}_{3}\right)$ plasma of PET films is well documented [10-12]. In accordance with operating parameters (pressure, power, time, gas flow rate), the quantity of nitrogen may reach $\approx 20 \%$ respectively on the surface of PET films [13] and the ratio $\mathrm{NH}_{2} / \mathrm{N}$ is in the order of $10-20 \%$ [12].

In this study, low pressure (ammonia gas precursor) RF plasmas is employed with variant treatment times $(1 \mathrm{~s}, 15 \mathrm{~s}, 60 \mathrm{~s}, 100 \mathrm{~s}, 200 \mathrm{~s})$ to create species on the surface of PET. PET film with flat surface and PET scaffold with porous surface are employed as testing materials. Amine groups are characterized and quantified by derivatization reaction (5-bromosalicylaldehyde is coupled with amino groups) in the vapour-phase and chemical species on modified surface are assessed by X-ray photoelectron spectroscopy (XPS). The evolution of the topography of PET film and PET scaffold surfaces are measured by atomic force microscopy (AFM) and scanning electron microscopy (SEM) techniques.

\section{Materials and methods}

Piece of PET films $(0.1 \mathrm{~mm}$ thickness, biaxial oriented) is purchased from Goodfellow (Huntingdon, England) while PET scaffolds are obtained from Institute of Materials Industrials (IMI) (Montréal, Canada). PET films and PET scaffold of $4 \mathrm{~cm} \times 1.6 \mathrm{~cm}$ are prepared 
in the shape of rectangle. Plasma treatments are performed in cylindrical plasma reactor. The precursor gas used was high purity ammonia gas (99.99\% purity) from Matheson Tri-Gas Inc. (Newark, CA, USA). The following parameters: pressure (300 mTorr) and power $(15 \mathrm{~W}$ with a radio frequency of $13.56 \mathrm{MHz}$ ) are kept constant during plasma treatment. Only the time is varied from $1 \mathrm{~s}$ to $200 \mathrm{~s}$. Chemical derivatization for amine quantification: reagent 5-bromosalicylaldehyde, $98 \%$ is purchased from Sigma Aldrich (Milwaukee, WI). Briefly, the reaction of vapor-phase chemical derivatization is achieved in sealed glass tube. The chemical derivatization reaction is proceeded for $2 \mathrm{~h}$ at $85^{\circ} \mathrm{C}$. XPS spectra are recorded using a PHI 5600-ci spectrometer (Physical Electronics, Eden Prairie, MN). A standard monochromatic aluminium X-ray source $\left(\mathrm{Al} K_{\alpha}=1486.6 \mathrm{eV}\right)$ at $300 \mathrm{~W}$ with neutralizer is used to record the survey spectra $(1200-0 \mathrm{eV})$ while high-resolution spectra is obtained by using the monochromatic magnesium X-ray source $(1253.6 \mathrm{eV})$ at $300 \mathrm{~W}$ without charging neutralization but with energy referencing. The detection is performed at $45^{\circ}$ with respect to the normal surface and three points were analysed. Surface of samples are investigated by JEOL JSM35CF SEM under a $1.5 \mathrm{kV}$ accelerating voltage. Magnification of $600 \times$ is used for imaging samples. An area of $1000 \mathrm{~nm} \times 1000 \mathrm{~nm}$ is scanned to obtain the topography of the surface of samples with AFM (Digital Instruments, Santa Barbara, CA) in tapping mode.

\section{Results and discussion}

XPS survey of untreated and treated PET is presented in Fig. 1. It confirms that modification of the PET film is successfully realised. Similar result is obtained for PET scaffold.

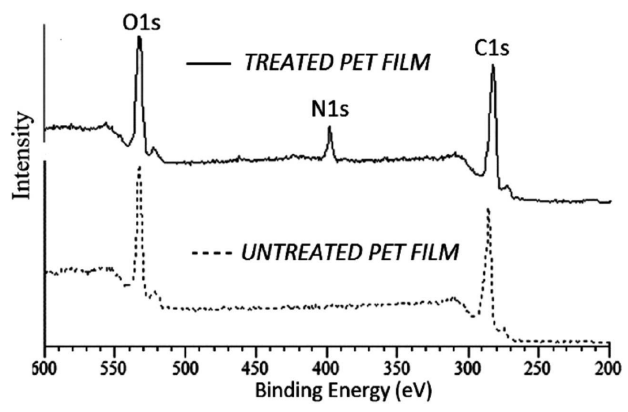

Fig. 1. Typical XPS survey spectra of untreated and treated PET film.

Amine $\left(\mathrm{NH}_{2}\right)$ concentration as a function of plasma treatment times were presented in Fig. 2a. Amazingly, after $1 \mathrm{~s}$ of treatment higher amount of amines is observed on the surface of PET; $1.65 \%$ and $1.80 \%$ for PET film and PET scaffold, compared to longer treatment times. It can be hypothesized that longer treatment time etches and damages surface such as chain scission and creation of unsaturation. Overall, shorter treatment time is effective

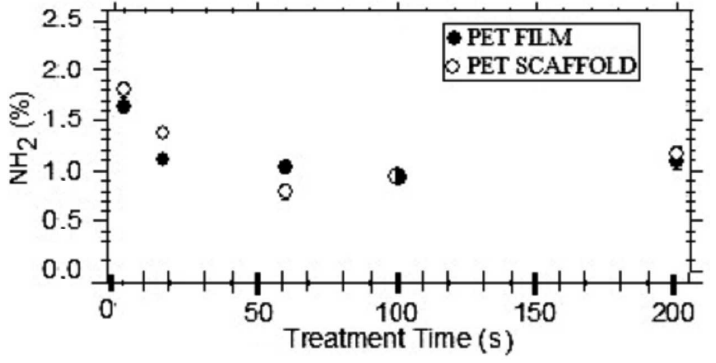

Fig. 2. Amine $\left(\mathrm{NH}_{2}\right)$ quantity of PET film and PET scaffold at different plasma treatment time.

to obtain higher amine quantity and seems not harmful for surface. High-resolution (HR) C $1 s$ XPS analyses of untreated and treated PET film is presented in Fig. 3. Untreated PET film and scaffold are mainly composed of three peaks; carbon atoms bound only to carbon or hydrogen in benzene ring $\mathrm{C}-\mathrm{C}(285.0 \mathrm{eV})$, to methylene carbons singly bound to oxygen $\mathrm{C}-\mathrm{O}(286.6 \mathrm{eV})$ and ester carbon atoms $\mathrm{O}-\mathrm{C}=\mathrm{O}(289.0 \mathrm{eV})$.

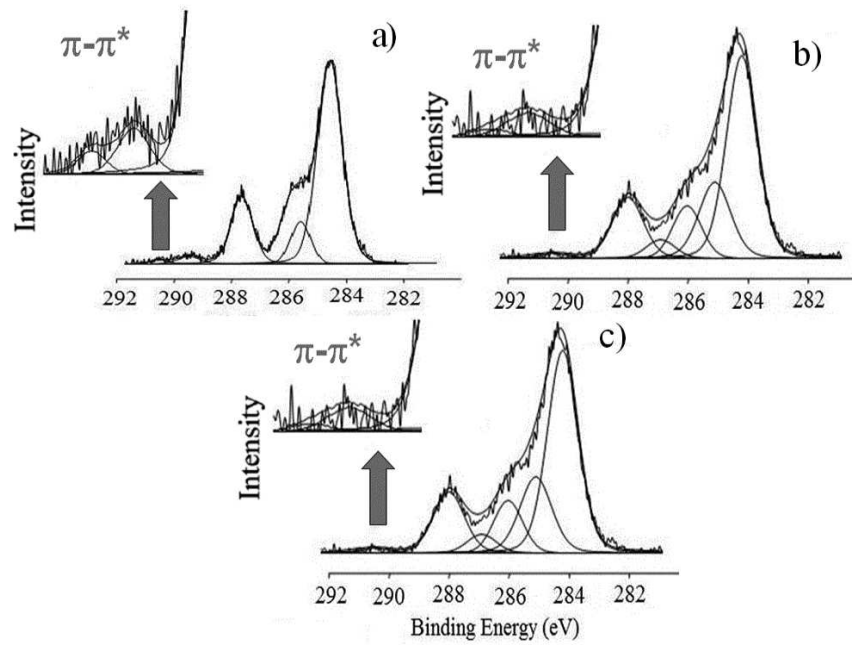

Fig. 3. C $1 s$ spectra analysis of PET film (a) untreated, (b) treated at $1 \mathrm{~s},(\mathrm{c})$ treated at $200 \mathrm{~s}$.

Those components are three most intense components, nevertheless at higher binding energy, we can observe $\pi-\pi^{*}(291.4 \mathrm{eV})$ shake-up satellite that corresponds to aromatic cycle in the chemical structure of PET (Fig. 3a).

After plasma treatment, a new peak is found at $287.4 \mathrm{eV}$ and corresponds to $\mathrm{N}-\mathrm{C}=\mathrm{O}$ and $\mathrm{N} \equiv \mathrm{C}$. In addition, nitrogen functionality $\mathrm{N}=\mathrm{C}$ is observed with $\mathrm{C}-\mathrm{O}$ at $286.6 \mathrm{eV}$. Girardeaux et al. [13] supposed that amines functions $\left(\mathrm{C}-\mathrm{NH}_{x}\right)$ is superimposed on the $\mathrm{C}-\mathrm{O}$ components. However, $\pi-\pi^{*}$ transition in relation with amine grafting was not presented in literature. We observed a significant decrease of higher binding energy of $\pi-\pi^{*}$ transition feature after plasma treatments (Fig. 3b and c). It would mean at the same time, a break-up of $\pi-\pi^{*}$ shake-up or opening of aromatic chain during the plasma treat- 
ment. Figure 4 presents SEM images of untreated and treated PET scaffold.

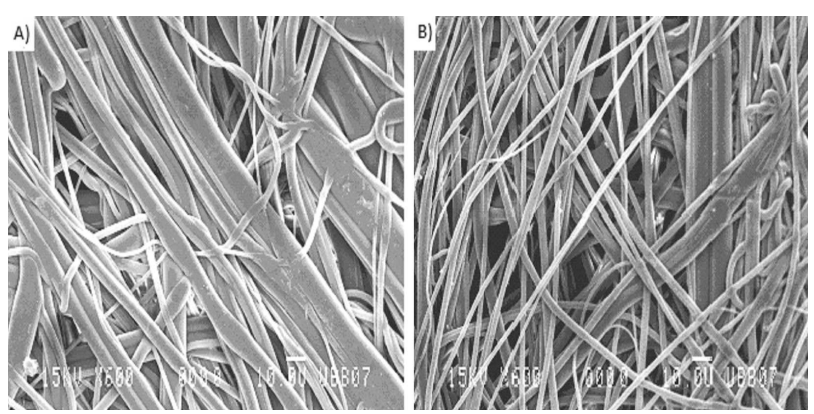

Fig. 4. SEM images of untreated and treated PET scaffold $(600 \times)$ : (A) untreated PET scaffold, (B) treated PET scaffold.

After plasma treatment SEM did not indicate any difference between untreated and treated PET scaffold.

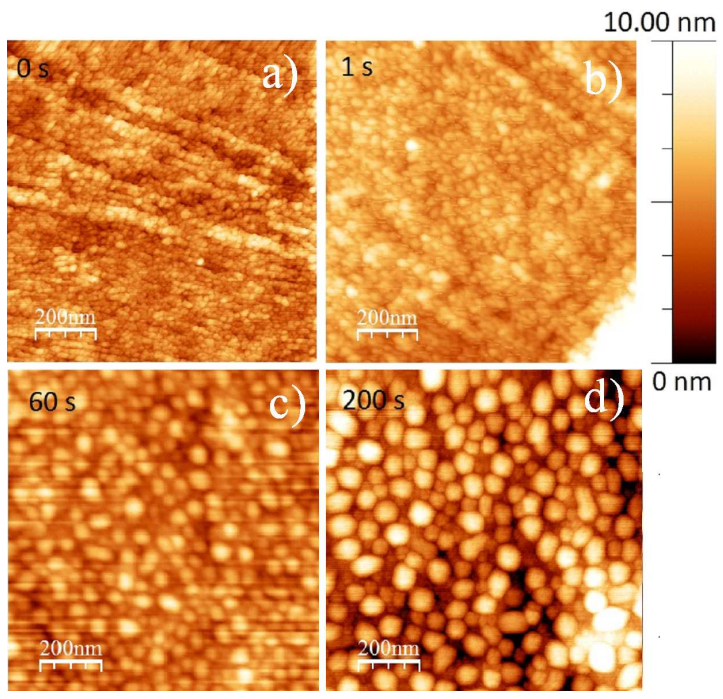

Fig. 5. 3D topography illustration of PET film surface before and after plasma treatment: (a) untreated, (b) $1 \mathrm{~s}$, (c) $60 \mathrm{~s}$, (d) $200 \mathrm{~s}$.

The evolution of the topography of the PET film and PET scaffold surfaces are measured by AFM analysis. Figure 5 shows the AFM image of the PET film as a function of exposure time. The untreated PET film is relatively smooth and constituted of nodules surface (Fig. 5a), in agreement with data published by different authors [16-18]. The average size of nodules are approximately $375 \mathrm{~nm}^{2}$ (Figs. 5a). After plasma treatment, the quantity of nodules is decreased and they become larger; the area surface of nodules approximately doubled comparing to original surface. The area surface of nodules can reach $6800 \mathrm{~nm}^{2}$ after $200 \mathrm{~s}$ of treatment (Fig. 5a). At higher plasma treatment time, their shapes turn into rounded-beads forms (Fig. 5b-d).

\section{Conclusions}

The results presented in this paper reveal that low pressure ammonia plasma performed at different treatment time $1 \mathrm{~s}, 15 \mathrm{~s}, 60 \mathrm{~s}, 100 \mathrm{~s}$ and $200 \mathrm{~s}$ successfully introduced nitrogen species functionalities on PET film and PET scaffold. Higher quantity was obtained with treatment at $1 \mathrm{~s}$ for both materials. Amine was grafted especially by broken aromatic chain. AFM studies reveal that after plasma treatment the surfaces of samples are altered; untreated PET film has conical protuberances surface while after plasma treatment nodules become larger-rounded.

\section{References}

[1] J. Mackay, G. Mensah, Atlas of Heart Disease and Stroke, World Health Organization, Geneva 2004.

[2] J.A. Berliner, M. Navab, A.M. Fogelman, J.S. Frank, L.L. Demer, P.A. Edwards, A.D. Watson, A.J. Lusis, Circulation 91, 2488 (1995).

[3] N. Chakfé, F. Dieval, F. Thaveau, S. Rinckenbach, O. Hassani, G. Camelot, B. Durand, J.-G. Kretz and European Research Group on Grafts Used in Vascular Surgery, "Substituts vasculaires", Annales Chirurgie 129, 301 (2004).

[4] F. Hayashi, Y. Okuda, M. Nakata, K. Natori, SEI Tech. Rev. 55, 83 (2003).

[5] J.A. Chinn, J.A. Sauter, R.E. Phillips, W.J. Kao, J.M. Anderson, S.R. Hanson, T.R. Ashton, J. Biomed. Mater. Res. 39, 130 (1998).

[6] P.A. Ramires, L. Mirenghi, A.R. Romano, F. Palumbo, G. Nicolardi, J. Biomed. Mater. Res. 51, 535 (2000).

[7] H.S. Khaira, H. Vohra, Eur. J. Vasc. End. Surg. Extra 1, 65 (2001).

[8] M. Pasic, W. Müller-Glauser, L. Von Segesser, B. Odermatt, M. Lachat, M. Turina, Eur. J. Cardiothorac. Surg. 10, 372 (1996).

[9] X. Wang, P. Lin, Q. Yao, C. Chen, World J. Surgery 31, 682 (2007).

[10] M. Aflori, M. Drobotă, D. Tîmpu, V. Bărboiu, in: 28th Int. Conf. Phenom. Ion. Gases Prague, Vol. 13, 2007, p. 727.

[11] K. Narushima, N. Yamashita, M. Fukuoka, N. Inagaki, Y. Isono, M.R. Islam, Jpn. Soc. Appl. Phys. 46, 4238 (2007).

[12] K. Schröder, A. Meyer-Plath, D. Keller, W. Besch, G. Babucke, Contrib. Plasma Phys. 41, 562 (2001).

[13] C. Girardeaux, N. Zammatteo, M. Art, B. Gillon, J.J. Pireaux, R. Caudano, Plasmas Polym. 1, 327 (1996). 